Adrienn HEGYI, Tünde KUTI, Zsófia KERTÉSZ, András SEBÖK,

Sara De PELSMAEKER, Xavier GELLYNCK, József LEHOTA

\title{
3.5. CONSUMER BEHAVIOUR AT THE IMPULSE PRODUCT WITH PRODUCT DEFECT
}

\begin{abstract}
Summary
The aim of the research was to understand and describe the praline consumption behaviour and effect of the product defect, blooming on the behaviour by using Theory of Planned Behaviour model in Hungary. The extended TPB model was used in the experiment. The whole experiment on extended Theory of Planned Behaviour model was also used in Belgium led by University of Ghent. The TPB model was extended with a new contrast as desire and the impact of negative experience on consumer behaviour was also examined via tasting session (N: 120). Totally 400 consumers were involved in the survey. The instruction from Ajzen was followed in the evaluation. As a part of it, the regression analysis was used to define the main factors having impact on the behaviour of the consumers. Based on the results we could conclude that the factor desire was influencing the behaviour together with behaviour intention. A positive desire to eat pralines pushed the consumer to actually eat pralines. The explanation of the variances increased when introducing the desire factor. Results also showed that however, the attitude effected greatly the Hungarian consumers, especially after a negative experience (e.g. eating pralines with product defect), the influence of the perceived behaviour control was stronger than the attitude or subjective norm and the effect of desire decreased.
\end{abstract}

Keywords: consumer behaviour, desire, impulse products,

\section{Introduction}

Chocolate is the most craved food in the world and has long been thought of as a pleasurable, hedonistic comfort food (Rodin et al. 1991; Rozin, Levin and Stoess, 1991). Comparing the food items apple and chocolate eating were found to improve mood but chocolate's effect was stronger (Macht and Dettmer, 2006)

Chocolate eating reduced negative mood after watching sad film; no effect was identified on positive mood Bad mood alleviated after eating palatable chocolate (up to $70 \%$ cocoa)-but the effect was very short-lived. Generally chocolate and filled chocolate are known for the arousal of sensory pleasure due to the specific melting behaviour, aroma and taste (Januszewska and Viaene, 2002; Mela, 2000; Parker et al., 2006, Pelsmaeker et al., 2014). Several authors indicate that the popularity of chocolate is closely related to the emotions it evokes with the consumer (Macht and Dettmer, 2006; Parker et al., 2006). Researchers have tried to define the negative emotion related to chocolate and the factor was named guilty (Fletcher et al. 2007; Frijters, 1993). Gaining weight and absence of self-control, negative effect on skin were proven to be beliefs triggering the guilty feeling (Dean et al. 2008; Lawless and Claassen, 1993)

However, the result is that the craving will eventually overwhelm the craver until the person experiences a breakdown of their efforts to diet in order to manage or lose weight (Cartwright et al. 2007). Such breakdowns have been shown to lead to an 
eating binge in which the person has eaten much more chocolate than desired (Gendall, et al. 1997). Martin (2010) stated that the chocolate effected the consumers in the following way: $73 \%$-puts me in a good mood; 60\%-makes me happy; 50\%-makes my temper disappear; 53\%-makes me feel better; 37\%-makes me feel relaxed; $63 \%$-the smell makes me crave/want it more; $67 \%$-seeing somebody else eat makes me want it and $70 \%$-preferred the smell to cakes/sweets. According to the previous statement Macht and Dettmer (2006) found that a significant effect exists with the emotions joy and guilt after eating a chocolate bar in everyday life. Joy was related to sensory pleasure whereas guilt appeared to be induced by negative thoughts associated with eating chocolate. The consumption of chocolate is thus difficult to identify as it is possibly related to specific emotional beliefs. Several studies (Ajzen, 1991; Fishbein, 1975; Perugini, 2001; Sparks, 2001); aimed to investigate the aspects which has and influence on the consumers' behaviour.

In one approach, the consumer behaviour refers to the selection, purchase and consumption of food for the satisfaction of their wants. Rossi et al., 2005 stated that initially the consumers try to find and select only those products which promise greater utility. After selection, the consumers estimate the available amount of money which they can spend. Lastly, the consumer analyses the prevailing prices of the products and taking the decision. Another point of view, not only the utility and the price of the product influence the consumers, but social, personal and cultural aspects as well. Furthermore, the consumption is not the only purpose to satisfy the basic needs, rather to achieve self-actualization and reach higher stages of Maslow-pyramid. This is why consumption also form the identity of the consumers and provide a social status as well.

The TPB (Ajzen, 1991; Fishbein, 1975; Perugini, 2001; Sparks, 2001) is applied to investigate the cognitive influences by which the rational behaviour of consumers is for prediction.

Januszewska and Viaene (2001) and Osman and Sobal (2006) studied the consumers' behaviours towards chocolate eating with Polish and Belgian consumers and Spanish and American ones. The chocolate craving was significantly different between Spanish and American consumers. Based on this studies we can conclude that different population have different behaviours towards eating chocolate as impulse product.

The evaluation of the product defects is a very complex problem, because the presence of the product defects in terms of quantity and qualitative aspects is well defined in the various legal requirements, but the consumers' opinions; understandings and behaviours on product with defects are slightly investigated in the different researches. The fat bloom and cracking are common problems in pralines leading to significant reduction of shelf-life and rejection of the products by consumers. It is a physical defect that is characterized as a whitish layer on the outer surface (Tisoncik, 2013). It is estimated that 143000 ton chocolate is affected by quality problems like fat bloom and cracks, which costs the European chocolate industry up to EUR 1.2 million a year (ProPraline, 2011).

Based on the literature review including the different cognitive models the models of Ajzen and Fishbein was used to investigate the consumers' behaviour aspects in our survey. The primary objective of this research is to investigate consumer behaviour 
towards filled chocolate consumption in Belgium and Hungary using the extended theory of planned behaviour (TPB) as a conceptual framework, including the emotional factor, desire. The second objective of our trial in Hungary was to examine the negative experience on the behavioural intention and behaviour of chocolate consumers. This article mainly focused on the Hungarian data.

\section{Theory of Planned Behaviour}

Ajzen and Fishbein (1980) developed the Theory of Reasoned Action (TRA) in order to identify the mechanisms of human behaviour in decision processes when this decision is based on free will. According to this theory, individuals are rational and motivation-based in their decision-making processes, and make a reasoned choice among various alternatives. TRA suggests that behaviour intention of a consumer is based on attitude (ATT) and subjective norm (SN). ATT are evaluative reactions to performing instrumental actions and are thought to be motivating the consumer to respond in a positive or negative manner to a certain action. They are modelled as functions of a decision maker's beliefs about the actions and the evaluation of these actions. The second predictor of behavioural intention, SN, captures the interpersonal aspects of behaviour which are largely based on the need for approval and is also referred to as compliance. The Theory of Planned Behaviour (TPB) is an extended version of the TRA. This theory considers not only volitional control (i.e. if a consumer can decide at will to perform or not perform a certain behaviour) but also non-volitional control (i.e., non-motivational factors such as time or money are important in performing behaviour) in explaining an individual's behaviour (Ajzen, 1991). Next to ATT and SN, it states that perceived behaviour control (PBC) is a third factor that helps explaining behaviour intention. PBC reflects the decisions maker's sense of control over performing the chosen actions in the decision enactment. It incorporates aspects of self-regulation, therefore it is a cognitive determinant for behavioural intention as well as behaviour. Further, Ajzen (1991) states that the stronger the intention to perform behaviour, together with perceived behaviour control, accounts for a major part of the variance in behaviour.

The TPB presumes that behaviour is a function of three types of salient beliefs relevant to the behaviour. The first type of beliefs are behavioural beliefs which influence attitudes towards behaviour.

These beliefs represent the subjective probability that the behaviour will produce the outcome in question. Second, the normative beliefs constitute the underlying determinants of subjective norms. These beliefs are concerned with the possibility that important individuals or groups will approve or disapprove the behaviour in question. The third ones are control beliefs that provide the basis for perceptions of behavioural control. Control beliefs can be based on several factors, e.g. past experience, secondhand information about the behaviour, experiences of other individuals and any other factor that increases or decreases the perceived difficulty of performing the behaviour in question.

Ajzen's model has been applied extensively in food studies to reveal and understand the drivers for consumer behaviour and behavioural intention (Mazzocchi et al., 2006; 
Perugini and Bagozzi, 2001). Literature indicated that desires have an influence on behaviour intention and behaviour of the consumer towards food products. This knowledge was translated into an extension of the TPB. Desire was introduced as a new construct that influences a consumer's behaviour (Hoppe. et al., 2013; Perugini and Bagozzi, 2001). This gave a tool to differentiate the Belgian and Hungarian consumer.

\section{Method}

An on-line survey was conducted in Hungary which structure was based on literature review, results of focus group studies and elicity studies.

The three parts of the on-line survey included questions to comprehend personal characteristics, intrinsic product characteristics and consumer behaviour. 400 consumer participated in the study. They were divided into 3 groups. Group A included 120 consumers who tasted the praline samples and filled the on-line survey as well. Consumers in Group B did not participate in the tasting session, but on their second test occasion they also filled the questionnaire again. Group $\mathrm{C}$, similar to Group B did not taste the model pralines, and they only answered questions related to the intrinsic product characteristics (Table 1).

Table 1: The construction of the research

\begin{tabular}{|l|c|c|c|c|c|c|}
\hline $\begin{array}{c}\text { Steps of the } \\
\text { research }\end{array}$ & $\begin{array}{c}\text { On-line } \\
\text { survey }\end{array}$ & $\begin{array}{c}\text { Taste } \\
\text { sensitivity of } \\
\text { target group }\end{array}$ & $\begin{array}{c}\text { Tasting } \\
\text { session }\end{array}$ & $\begin{array}{c}\text { Tasting } \\
\text { session }\end{array}$ & $\begin{array}{c}\text { Tasting } \\
\text { session }\end{array}$ & $\begin{array}{c}\text { Repeated } \\
\text { on-line } \\
\text { survey }\end{array}$ \\
\hline & Step 1-2. & Step 3. & Step 4. & Step 5. & Step 6. & Step 7. \\
\hline $\begin{array}{l}\text { General part } \\
\text { (on-line survey) }\end{array}$ & $\begin{array}{c}\text { N:400 } \\
\text { (HU) }\end{array}$ & & $120 / 459$ & $120 / 459$ & $120 / 459$ & \\
\hline $\begin{array}{l}\text { Group A: Sight+ } \\
\text { tasting }\end{array}$ & 400 & $120 / 400$ & $120 / 400$ & $120 / 400$ & $120 / 400$ & $120 / 400$ \\
\hline Group B: Sight & & & & & & $120 / 400$ \\
\hline $\begin{array}{l}\text { Group C: Sight+ } \\
\text { methodology } \\
\text { (like, dislike) }\end{array}$ & & & & & & $120 / 400$ \\
\hline Group D & & & & & & $40 / 400$ \\
\hline
\end{tabular}

Source: own research

The traditional TPB was built to understand the behaviour intention (BI) of a consumer to purchase a product. Three constructs are important to explain BI: attitude towards product (ATT), subjective norm (SN), perceived behaviour control (PBC). The model was analysed through several interrelated components. Behaviour (B) was predicted by intention to perform this behaviour. Subsequently, behavioural intention (BI) was predicted from three components as follows.

First, there was an attitude (ATT), explained as evaluation whether the individual sees the behaviour as bad or good, unpleasant or pleasant, harmful or beneficial. Attitudes were calculated from 'behavioural beliefs' that performing a certain behaviour leaded to a particular outcome and the 'outcome evaluation' of behaviour, i.e., the evaluation of desirability of that outcome. 
The second component stood for subjective norm (SN). This was the perception by an individual of social pressure from important other people to perform a particular behaviour. The subjective norms were computed from 'normative beliefs' concerning the influence of a referent (e.g. family or friends), and 'motivation to comply' with this referent. The third construct was called perceived behavioural control (PBC). The PBC component could also be explained as the degree to which a person felt that she/he was in control of her/his own behaviour.

Regression analysis was done to determine how much the behaviour intention of a consumer was related to ATT, SN and PBC. Additionally, the correlation coefficients between the three constructs and behaviour intention were calculated.

A second regression analysis determined how behaviour intention is explaining the actual behaviour of a consumer.

A third regression was done to reveal how the behaviour intention and the perceived behaviour control together explain the behaviour. The calculation was done with perceived behaviour control and with attitude and subjective norm. This method could indicate what constructs influence not only behaviour intention but together with behaviour intention, the actual behaviour of the consumer.

Desire as a new construct was added to the model. The influence of desire was calculated with regression analysis. Desire was then put as an extra construct when defining behaviour intention. It also was used to explain actual behaviour together with behaviour intention.

The impact of the negative experience with blooming praline was also investigated.

\section{Results}

\section{Consumer behaviour towards filled chocolate consumption in Hungary using the extended theory of planned behaviour (TPB)}

Firstly reliability with Cronbach's alpha was checked on the main elements (ATT, SN, PBC) of the TPB model. The reliability for attitude and perceived behavioural control were rather low but sufficient, for subjective norm the Chronbach's alpha was very high. After the reliability check, the values for the different constructs were calculated. These new variables were defined as direct_att, direct_sn and direct_pbc. The correlations between the construct and the questions were calculated. All the correlation coefficients were significant which indicated that none of the questions should be left out of the calculation. A next step was defining the value for behavioural intention (BI) and behaviour (B). A reliability analysis was first executed. Both constructs had a high Chronbach's alpha (0.879). Correlation coefficients were calculated to indicate which question was highly correlating with the construct. All the correlation coefficients were significant and the values were high. done for the Hungarian consumers to explain the behavioural intention and the behaviour of the consumers (Table 2). The beta coefficients were the regression coefficients of the independent variables. For behavioural intention, attitude and perceived behavioural control were significant with $\mathrm{p}<0.001$. Subjective norm was also significant but with $\mathrm{p}<0.01$. This indicated that the Hungarian consumer was influenced by the three constructs attitude, subjective norm and perceived behaviour control. 
Table 2: Regression analysis of theory of planned behaviour for the Hungarian consumers

\begin{tabular}{|l|l|l|l|l|l|}
\hline Dependent variable & Independent variable & Beta & Sign. & Correlation & Sign. \\
\hline Direct_bi & Direct_att & 0.406 & 0.000 & 0.407 & 0.000 \\
$\mathbf{R}^{2}=\mathbf{0 . 2 2 3}$ & Direct_sn & 0.123 & 0.008 & 0.238 & 0.000 \\
& Direct_pbc & -0.185 & 0.000 & -0.157 & 0.001 \\
\hline Direct_b & Direct_bi & 0.792 & 0.000 & 0.792 & 0.000 \\
$\mathbf{R}^{\mathbf{2}=\mathbf{0 . 6 2 7}}$ & & & & & \\
\hline Direct_b & Direct_bi & 0.781 & 0.000 & 0.792 & 0.000 \\
$\mathbf{R}^{\mathbf{2}=\mathbf{0 . 6 3 3}}$ & Direct_pbc & -0.074 & 0.017 & -0.196 & 0.000 \\
\hline Direct_b & Direct_bi & 0.795 & 0.000 & 0.792 & 0.000 \\
$\mathbf{R}^{2}=\mathbf{0 . 6 2 8}$ & Direct_att & -0.008 & 0.807 & 0.316 & 0.000 \\
\hline Direct_b & Direct_bi & 0.786 & 0.000 & 0.792 & 0.000 \\
$\mathbf{R}^{2}=\mathbf{0 . 6 2 7}$ & Direct_sn & 0.024 & 0.447 & 0.211 & 0.000 \\
\hline
\end{tabular}

Source: own research

The regression coefficient of attitude was the highest coefficient and positive $(\beta=0,406)$. This meant the behaviour of the Hungarian consumer was highly depended on the attitude of the consumer towards the product. It can be stated that a positive attitude was positively influencing the behaviour intention of the Hungarian consumers. The beta value for subjective norm was low but positive $(\beta=0.123)$. A Hungarian consumer was influenced by his/her partner, family and friends to eat or reject pralines. Again a positive influence from these people increased the behaviour intention of the consumer. Perceived behavioural control had a negative beta value $(\beta=-0.185)$. The explained variance, $R^{2}$, was low which indicated that these were only a few factors that explained the intention to buy a product $\left(\mathrm{R}^{2}=0.223\right)$.

The correlation coefficients represented the same trends. However, these coefficients were all significant, which meant that there was a correlation between all constructs and behavioural intention.

Behaviour could be constructed in different ways. When the regression analysis was done with only behaviour intention, the explained variance was almost $63 \%$. When including perceived behaviour control, the results indicated that the regression coefficient was significant with $\mathrm{p}<0.05$ but the increase of the explained variance was low. Identical to the explanation of the behaviour intention, the perceived behaviour control had a negative regression coefficient. When explaining behaviour with behaviour intention and attitude, the results indicated that attitude was not significantly relevant in explaining this construct. The same result was found when including subjective norm in the regression analysis. The conclusion here was that Hungarian consumers were only influenced by their perceived behavioural control in actual behaviour of eating pralines and not by attitude or subjective norm.

In the Extended Theory of Planned Behaviour, the extra construct desire (direct_d) was included. Before calculating the value for this construct, the internal validity was checked. These Chronbach's alpha was high, so no problems occurred in calculating the value for desire. Again the correlation coefficients were calculated to indicate if the questions were correlating to the construct. These results indicated that the coefficients were significant. The correlation with the construct score was high.

The regression analysis was then executed to indicate how big the influence of this construct was on behavioural intention and behaviour (Table 3 ). 
Table 3: Regression analysis of extended TPB for Hungarian consumers

\begin{tabular}{|c|c|c|c|c|c|}
\hline Dependent variable & Independent variable & Beta & Sign. & Correlation & Sign. \\
\hline Direct_bi & Direct_att & 0.244 & 0.000 & 0.407 & 0.000 \\
\hline \multirow[t]{3}{*}{$R^{2}=0 . \overline{444}$} & Direct sn & 0.058 & 0.143 & 0.238 & 0.000 \\
\hline & Direct_pbc & -0.070 & 0.081 & -0.157 & 0.001 \\
\hline & Direct d & 0.516 & 0.000 & 0.620 & 0.000 \\
\hline Direct_b & Direct_bi & 0.681 & 0.000 & 0.792 & 0.000 \\
\hline$R^{2}=0 . \overline{647}$ & Direct $\mathrm{d}$ & 0.180 & 0.001 & 0.602 & 0.000 \\
\hline
\end{tabular}

Source: own research

The regression analysis to explain behavioural intention gave other results than in the traditional TPB. The construct desire resulted in a higher explained variance namely from an $\mathrm{R}^{2}$ of 0.223 to 0.444 . Further, only the regression coefficients of attitude and desire were significant. Subjective norm stayed non-significant but perceived behavioural control was now also non-significant. The coefficient for attitude was a little lower than before. The regression coefficient of desire was high and almost equal to the beta value for attitude. The correlation coefficients were all significant, which indicated that they were all correlated to the behaviour intention.

The regression analysis to define the behaviour of the consumer indicated that the factor desire was influencing the behaviour together with behaviour intention. A positive desire to eat pralines pushed the consumer to actually eat pralines. The explanation of the variances increased when introducing the desire factor.

\section{The negative experience on the behaviour of filled chocolate consumers}

The impact of negative experience, $2^{\text {nd }}$ occasion can be presented through the results. The people in the $2^{\text {nd }}$ occasion not just were introduced with the pralines, but the pralines with products defects, blooming as well.

Table 4: Regression analysis of 1st and 2nd occasions

\begin{tabular}{|c|c|c|c|c|c|c|c|c|c|}
\hline $\begin{array}{c}\text { Dependent } \\
\text { variable }\end{array}$ & $\begin{array}{c}\text { Independent } \\
\text { variable }\end{array}$ & Beta & Beta_2 & Sign. & $\begin{array}{c}\text { Sign. } \\
2\end{array}$ & $\begin{array}{l}\text { Corre- } \\
\text { lation }\end{array}$ & $\begin{array}{c}\text { Corre- } \\
\text { lation_2 }\end{array}$ & Sign. & $\begin{array}{c}\text { Sign. } \\
2\end{array}$ \\
\hline Direct_bi & Direct_att & 0,406 & 0,236 & 0,000 & 0,002 & 0,407 & 0,198 & 0,000 & 0,01 \\
\hline $\mathrm{R}_{1}^{2}=0.223$ & Direct_sn & 0,123 & 0,112 & 0,008 & 0,099 & 0,238 & 0,127 & 0,000 & 0,027 \\
\hline $\mathrm{R}_{2}^{2}=\mathbf{0 , 1}$ & Direct_pbc & $-0,185$ & $-0,071$ & 0,000 & 0,364 & $-0,157$ & 0,015 & 0,001 & 0,409 \\
\hline Direct_b & Direct_bi & 0,792 & 0,659 & 0,000 & 0,000 & 0,792 & 0,659 & 0,000 & 0,000 \\
\hline $\begin{array}{l}R_{1}^{2}=\mathbf{0 . 6 2 7} \\
R_{2}{ }_{2}=\mathbf{0 , 4 3 5}\end{array}$ & & & & & & & & & \\
\hline Direct_b & Direct_bi & 0,781 & 0,658 & 0,000 & 0,000 & 0,792 & 0,659 & 0,000 & 0,000 \\
\hline $\begin{array}{l}R_{1}^{2}=0.633 \\
R_{2}^{2}=0,442\end{array}$ & Direct_pbc & $-0,074$ & 0,083 & 0,017 & 0,095 & $-0,196$ & 0,093 & 0,000 & 0,080 \\
\hline Direct_b & Direct_bi & 0,795 & 0,67 & 0,000 & 0,000 & 0,792 & 0,659 & 0,000 & 0,000 \\
\hline $\begin{array}{l}R_{1}^{2}=0.628 \\
R_{2}{ }_{2}=0,438\end{array}$ & Direct_att & $-0,008$ & $-0,055$ & 0,807 & 0,276 & 0,316 & 0,077 & 0,000 & 0,120 \\
\hline Direct_b & Direct_bi & 0,786 & 0,685 & 0,000 & 0,000 & 0,792 & 0,659 & 0,000 & 0,000 \\
\hline $\begin{array}{l}R_{1}^{2}=0.627 \\
R_{2}{ }_{2}=0,476\end{array}$ & Direct_sn & 0,024 & $-0,205$ & 0,447 & 0,000 & 0,211 & $-0,118$ & 0,000 & 0,037 \\
\hline
\end{tabular}

Notes: the bottom index (2) means the second occasion.

Source: own research 


\begin{tabular}{|c|c|c|c|c|c|c|c|c|c|}
\hline $\begin{array}{c}\text { Dependent } \\
\text { variable }\end{array}$ & $\begin{array}{c}\text { Independent } \\
\text { variable }\end{array}$ & Beta & Beta_2 & Sign. & $\begin{array}{c}\text { Sign. } \\
2\end{array}$ & $\begin{array}{c}\text { Correla } \\
\text {-tion } \\
\end{array}$ & $\begin{array}{c}\text { Correla- } \\
\text { tion_2 }\end{array}$ & Sign. & $\begin{array}{c}\text { Sign. } \\
2\end{array}$ \\
\hline Direct_bi & Direct_att & 0,244 & 0,132 & 0,000 & 0,08 & 0,407 & 0,198 & 0,000 & 0,001 \\
\hline \multirow{3}{*}{$\begin{array}{l}R^{2}{ }_{1}=0.444 \\
R^{2}{ }_{2}=0,148\end{array}$} & Direct_sn & 0,058 & 0,03 & 0,143 & 0,66 & 0,238 & 0,127 & 0,000 & 0,017 \\
\hline & Direct_pbc & $-0,070$ & 0,044 & 0,081 & 0,577 & $-0,157$ & 0,015 & 0,001 & 0,409 \\
\hline & Direct_d & 0,516 & 0,319 & 0,000 & 0,000 & 0,620 & 0,336 & 0,000 & 0,000 \\
\hline Dir & Direct bi & 0,681 & 0,71 & 0,000 & 0,000 & 0,792 & 0,659 & 0,000 & 0,000 \\
\hline $\begin{array}{l}R_{1}^{2}=0.647 \\
R_{2}{ }_{2}=0,455\end{array}$ & Direct_d & 0,180 & $-0,151$ & 0,001 & 0,004 & 0,602 & 0,087 & 0,000 & 0,094 \\
\hline
\end{tabular}

Notes: the bottom indexx (2) means the second occasion.

\section{Source: own research}

Firstly, reliability with Cronbach's alpha was checked on the main elements (ATT, $\mathrm{SN}, \mathrm{PBC}$ ) of the TPB model. The reliability for attitude, subjective norm and perceived behavioural control were low but sufficient.

After the reliability check, the values for the different constructs were calculated. These new variables were again defined as direct_att, direct_sn and direct_pbc in the same way as it presented in 4.1. A reliability analysis was executed on behaviour and behaviour intention that was sufficient for the further analysis.

Regression analysis was done for the Hungarian consumers to explain the behavioural intention and the behaviour of the consumers (Table 4). For behavioural intention, attitude was significant with $\mathrm{p}<0,05$, but the subjective norm, the perceived behavioural control were not significant. This indicated that the Hungarian consumer was influenced by mainly the construct, attitude and not as much by perceived behaviour control, subjective norm. Based on the results we can conclude that behavioural intention (BI) still influenced the consumer's behaviour mainly.

In the $2^{\text {nd }}$ occasion the extended TPB with the use of the new construct, desire was used. As a results of the second occasion, the negative impact the desire and the attitude have significant impacts on behaviour intention. Subjective norm, perceived behavioural control stayed non-significant.

The regression analysis to define the behaviour of the consumer indicated that the factor desire was influencing the behaviour together with behaviour intention. However a positive desire to eat pralines pushed the consumer to actually eat pralines. Desire (D) stayed significant on behaviour, but it seemed that negative experience had a negative effect on the desire.

\section{Conclusion}

In the literature, the Theory of Planned Behaviour (TPB) has proven to be effective in understanding the consumer behaviour towards food, chocolate and the praline in particular. The TPB was applied to investigate the cognitive influences by which the rational behaviour of consumers may be predicted. The model was analysed through several interrelated components, behaviour (B), attitude (ATT), subjective norm (SN) and perceived behaviour control (PBC). Later, the model was extended with desire as a new construct. The behaviour of Hungarian consumers was influenced by behaviour intention and desire according the extended TPB model. 
Behaviour intention was affected by the negative perceived behaviour control, the attitude and the subjective norm in terms of traditional TPB. Behaviour intention was affected significantly by attitude and desire, non-significantly by subjective norm and negatively perceived behaviour control at the extended TPB. The behaviour was explained by behaviour intention. The behaviour was explained better with the use of desire, with the extended TPB. The impact of the knowledge of product defect, blooming, negative experience had negative effect on desire.

\section{References}

1. Ajzen, I., (1991): The Theory of Planned Behaviour. Organizational behaviour and human decision processes, 50(2), 179-211. DOI: 10.1016/0749-5978(91)90020-T

2. Ajzen I.; Fishbein M. (1980): Understanding Attitudes and Predicting Social Behaviour. Prentice Hall: Englewood Cliffs, NJ, p. 50-57.

3. Anonymous (1975): Minutes of Division Business meeting. In: Institute of Food Technologists -Sensory Evaluation Division, IFT Chicago, IL.

4. Cartwright, F.; Stritzke, W. G. K.; Durkin, K.; Houghton, S.; Burke, V.; Beilin, L. J. (2007): Chocolate craving among children: Implications for disordered eating patterns. Appetite, 48(1), 87-95. http://dx.doi.org/10.1016/j.appet.2006.07.081

5. Dean, M.; Raats, M. M.; Shepherd, R. (2008). Moral Concerns and Consumer Choice of Fresh and Processed Organic Foods. Journal of Applied Social Psychology, 38(8), 2088-2107.

6. Fletcher, B. C.; Pine, K. J.; Woodbridge, Z.; Nash, A. (2007): How visual images of chocolate affect the craving and guilt of female dieters. Appetite, 48 (2), 211-217p.

7. Fishbein, M.; Ajzen, (1975): Belief, attitude, intention and behaviour: an introduction to theory and research. Addison-Wesley, 578p.

8. Frijters, J. E. R. (1993): Functional measurement in the study of mixture percepts. 626 Chemical Senses, 18(2), 93-100 p.

9. Gendall, K. A.; Joyce, P. R.; Sullivan, P. F. (1997): Impact of definition on prevalance of food cravings in a random sample of young women. Appetite, 28, 63-72.doi: 10.1006/appe.1996.0060.

10. Hoppe, A.; Vieira, L. M.; Barcellos, M. D. (2013): Consumer behaviour towards organic food in porto alegre: an application of the theory of planned behaviour. Rev. Econ. Sociol. Rural vol. 51, pp. 69-90. http://dx.doi.org/10.1590/S0103-20032013000100004

11. Januszewska, R.; Viane, J, (2002): Acceptance of chocolate by preference cluster mapping across Belgium and Poland. Journal of Euromarketing, 11 (1), 61-86p.

12. Lawless, H. T.; Claassen, M. R. (1993). Application of the central dogma in sensory evaluation. Food Technology, 47(6), 139-146

13. Macht, M.; Dettmer, D. (2006): Everyday mood and emotions after eating a chocolate bar or an apple. Appetite, 46(3), 332-336p. http://dx.doi.org/10.1016/j.appet.2006.01.014

14. Martin, N. G. (2009): Chocolate psychology: what science tells us about its effect on behaviour. In: London International Confectionery Conference,, 1st-2nd December 2009, British Museum, London.

15. Mazzocchi, M.; Lobb, A. E. W.; Traill, B. (2006): Food Scares and Consumer Behaviour: A European Perspective. Presentation at the International Association of Agricultural Economists Conference, Gold Coast, Australia, August 12-18, 2006.

16. Mela, D. J. (2000): Why do we like what we like? Journal of the Science of Food and Agriculture, 81, 10-16. 
17. Osman, J. L.; Sobal, J. (2006): Chocolate cravings in American and Spanish individuals: Biological and cultural influences. Appetite, 47, 290-301. http://dx.doi.org/10.1016/j.appet.2006.04.008

18. Perugini, M.; Bagozzi, R.P., (2001): The role of desires and anticipated emotions in goaldirected behaviours: Broadening and deepening the theory of planned behaviour. British Journal of Social Psychology, 40, 79-98p.

19. Parker, G.; Parker, I., Brotchie, H. (2006): Mood state effects of chocolate. Journal of Affective Disorders, 92(2-3), 149-159.

20. Parker, D.; Manstead, A. S. R.; Stradling, S. G.; Reason, J. T.; Baxter, J. S. (1992): Intention to Commit Driving Violations: An Application of the Theory of Planned Behaviour. Journal of Applied Psychology, 77(1), 94-101p.

21. Pelsmaeker, S.; Gellynck, X.; Delbaere, C.; Declercq, N.; Dewettinck, K. (2014): Consumerdriven product development and improvement combined with sensory analysis: A case-study for European filled chocolates. Food quality and preference ,41, pp. 20-29. http://dx.doi.org/10.1016/j.foodqual.2014.10.009

22. Propraline (2011): URL:_www.propraline.eu.com

23. Rodin, J., Mancuso, J., Granger, J., Nelbach, E. (1991): Food cravings in relation to body mass index, restraint and estradiol levels: A repeated measures study in healthy women. Appetite, 17, 177-185. doi: 10.1016/0195-6663(91)90020-S

24. Rozin, P., Levine, E. Stoess, C. (1991): Chocolate craving and liking. Appetite, 17(3), 199212. http://dx.doi.org/10.1016/0195-6663(91)90022-K

25. Rossi, P. E.; Allenby, G.M.; Mcculloch, R. (2005): Modeling interdependent consumer behaviour. Bayesian Statistic and Marketing, John Wiley \& Sons. Ltd. ISBN: 0470863676.

26. Shepherd, R.; Sparks, P.; Guthrie C.A. (1995): The Application of the Theory of Planned Behaviour to Consumer Food Choice", in E - European Advances in Consumer Research Volume 2, eds. Flemming Hansen, Provo, UT : Association for Consumer Research, Pages: 360-365.

27. Tisoncik, M (2013): Chocolate fat bloom. http://www.blommer.com/ documents/ChocolateFat-Bloom-article.pdf 